\title{
First record of Loricifera from the Iberian Peninsula, with the description of Rugiloricus manuelae sp. nov., (Loricifera, Pliciloricidae)
}

\author{
Fernando Pardos • Reinhardt Møbjerg Kristensen
}

Received: 27 November 2012/Revised: 31 January 2013/Accepted: 9 February 2013/Published online: 13 March 2013

(C) Springer-Verlag Berlin Heidelberg and AWI 2013

\begin{abstract}
Sediment samples were taken along the Cantabric platform (Northern Spain) from 200 to 600 meters depth in October 1990. Forty specimens of loriciferans were sorted out of the samples, of which 38 specimens belong to a new species of Rugiloricus. The new species, $R$. manuelae sp. nov., was investigated with both light (DIC) and electron microscopy (SEM). Complete descriptions of both adult and larval stages are provided, including mapping of the introvert scalids for both stages. Information from a molting stage with an adult male inside confirms conspecificity of larvae and adults. The presence of a highly reduced postlarval stage leaded to the suggestion of a new modified life cycle for the family Pliciloricidae.
\end{abstract}

Keywords Loricifera - Meiofauna - Cantabric Sea Postlarva $\cdot$ Life cycle

\section{Introduction}

Loricifera is a phylum of exclusively marine meiofaunal animals up to $1,000 \mu \mathrm{m}$ in length, although most of the known species do not exceed $300 \mu \mathrm{m}$. They have been found generally living in coarse sediments and subtidally, from relatively shallow waters (Higgins and Kristensen

Communicated by H.-D. Franke.

\section{F. Pardos $(\bowtie)$}

Departamento de Zoología y Antropología Física,

Facultad de Biología, Universidad Complutense, Madrid, Spain

e-mail: fpardos@bio.ucm.es

R. M. Kristensen

Zoological Museum. Natural History Museum of Denmark,

University of Copenhagen, Copenhagen, Denmark
1986; Todaro and Kristensen 1998; Kristensen and Gad 2004) to the deep sea (e.g., Kristensen and Shirayama 1988; Gad 2005c, 2009). Recently, loriciferans have been reported living permanently in extreme environments, such as a hypersaline, anoxic basin of the Mediterranean Sea (Danovaro et al. 2010, 2012). The phylogenetic position of Loricifera remains still controversial (for review, see Sørensen et al. 2008).

The phylum Loricifera (Kristensen 1983) is one of the latest described phyla of the twentieth century. Since its discovery, 32 species have been described (Higgins and Kristensen 1986; Kristensen and Shirayama 1988; Todaro and Kristensen 1998, Gad 2004, 2005b, c; Kristensen and Gad 2004; Gad and Martínez Arbizu 2005; Heiner and Kristensen 2005, 2009; Heiner and Neuhaus 2007; Kristensen et al. 2007, 2013; Heiner 2008), although about 80 more are known and awaiting description (Gad 2005a; Bang-Berthelsen 2008). The described species are grouped into three families, Nanaloricidae Kristensen, 1983, Pliciloricidae Higgins and Kristensen, 1986 and Urnaloricidae Heiner and Kristensen, 2009. Up to now, Nanaloricidae comprise six genera, Nanaloricus Kristensen, 1983; Armorloricus Kristensen and Gad, 2004; Phoeniciloricus Gad, 2004; Spinoloricus Heiner and Neuhaus, 2007; Culexiregiloricus Gad, 2009; and Australoricus Heiner et al., 2009. The family Pliciloricidae comprises three genera, Pliciloricus Higgins \& Kristensen, 1986, Rugiloricus Higgins \& Kristensen, 1986 and Titaniloricus Gad, 2005, with twelve, six and one species, respectively. The family Urnaloricidae presently has a single genus, Urnaloricus Heiner and Kristensen, 2009.

The three first described species of Rugiloricus, $R$. carolinensis, $R$. cauliculus and $R$. ornatus have been reported from Southeastern United States coastal waters (Higgins and Kristensen 1986). Only recently, three more 
Fig. 1 Map of the collecting sites for $R$. manuelae sp. nov. Inset shows the Cantabric Coast. See Table 1 for geographic coordinates of sampling localities

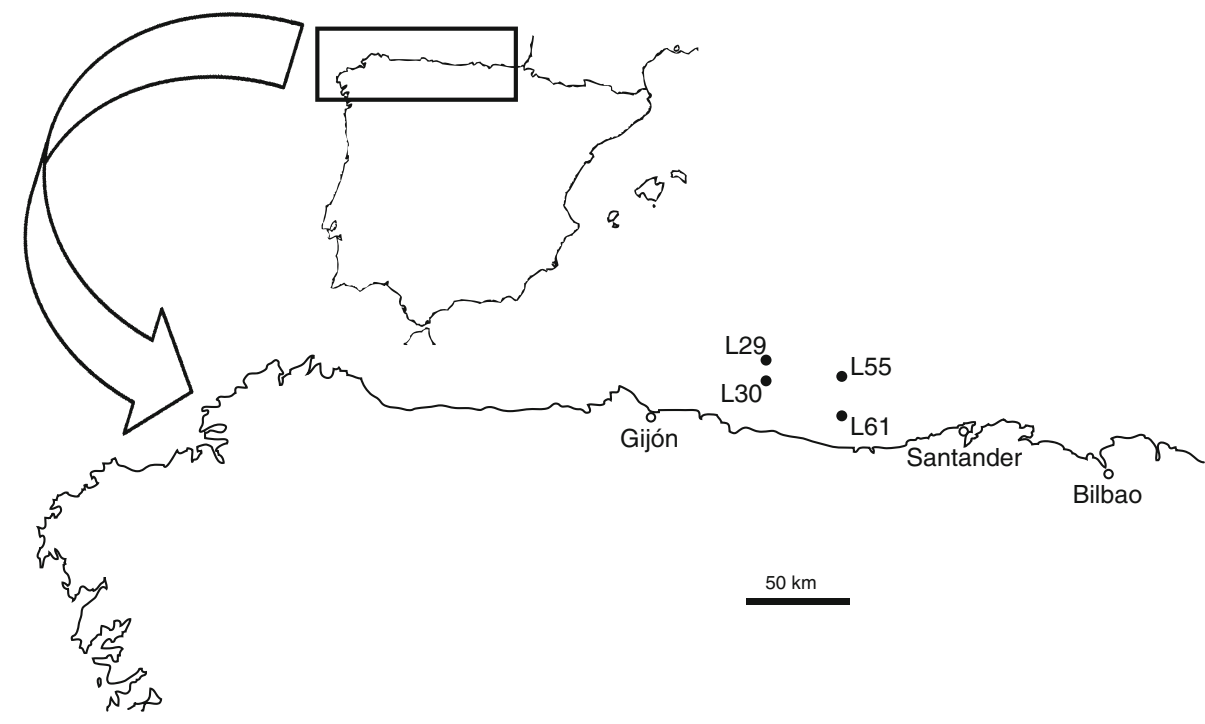

species have been described: $R$. polaris Gad \& Martinez Arbizu, 2005 from arctic waters, $R$. bacatus Heiner, 2008 from the Faroe Bank and $R$. renaudae Kristensen et al. 2013 from the channel of Mozambique. This genus has been found to have a complex life cycle, with several larval and postlarval stages prior to the adult (Kristensen and Brooke 2002; Heiner 2008; Bang-Berthelsen et al. 2012).

This paper describes a new species of Rugiloricus from the north coast of the Iberian Peninsula (Cantabric Sea) that constitutes the first record for the genus in Southern European waters and also the first record of a loriciferan in Spanish waters. The data reported here contribute to a better knowledge of the life cycle and biology of the genus and the Loricifera as a whole.

\section{Materials and methods}

Sediment samples were taken during the fisheries research cruise of the oceanographic vessel Cornide de Saavedra in October 1990 along the Cantabric platform (N Spain, Fig. 1). Qualitative samples were taken with a steel cylinder $40 \mathrm{~cm}$ long and $15 \mathrm{~cm}$ of diameter tied to the mouth of a bottom fishery net and closed at one end by a $62 \mu \mathrm{m}$ net. Each sample had an approximative volume of $2,190 \mathrm{~cm}^{3}$. A total of 40 loriciferan specimens were obtained from samples no. L-29, L-30, L-55 and L-61, between 200 and $600 \mathrm{~m}$ depth (Table 1); nearly, all belonged to the new Rugiloricus species described in this paper, but two specimens-one adult and one larvabelong to the genus Pliciloricus. The sediment of the Loricifera-containing samples was medium coarse sand with variable amounts of organic matter and mud.
Table 1 Sampling localities including details on depth and number of the 40 specimens

\begin{tabular}{llll}
\hline Sample & Locality & $\begin{array}{l}\text { Depth } \\
(\mathrm{m})\end{array}$ & $\begin{array}{l}\text { No. of } \\
\text { specimens }\end{array}$ \\
\hline L-29; 5 Oct.1990 & $5^{\circ} 00^{\prime} \mathrm{W}, 43^{\circ} 45^{\prime} \mathrm{N}$ & 350 & 33 \\
L-30; 9 Oct.1990 & $5^{\circ} 00^{\prime} \mathrm{W}, 43^{\circ} 41^{\prime} \mathrm{N}$ & 200 & 1 (Holotype) \\
L-55; 12 Oct. 1990 & $4^{\circ} 33^{\prime} \mathrm{W}, 43^{\circ} 41^{\prime} \mathrm{N}$ & 500 & 2 \\
L-61; 13 Oct. 1990 & $4^{\circ} 33^{\prime} \mathrm{W}, 43^{\circ} 31^{\prime} \mathrm{N}$ & 600 & 4 \\
\hline
\end{tabular}

See Fig. 1 for location

Samples were processed on board following the bubbling extraction technique for meiofauna (Higgins 1964, 1988), fixed with $7 \%$ buffered formalin and stained with Rose Bengal. Loriciferan specimens were sorted with an Irwin loop under a dissection microscope. The single adult male was prepared for light microscopy (Glycerol and modified Hoyer's medium, Higgins 1988) on a Cobb aluminum slide frame mount, and the larvae were prepared for both light microscopy and scanning electron microscopy. Light microscopy research was done using an Olympus BX51 microscope equipped with Nomarski interference contrast. SEM research was accomplished using a JEOL JSM-6335-F Scanning Electron Microscope.

\section{Results}

Phylum Loricifera Kristensen, 1983. Order Nanaloricida Kristensen, 1983. Family Pliciloricidae Higgins and Kristensen, 1986. Genus Rugiloricus Higgins and Kristensen, 1986. Rugiloricus manuelae sp. nov. 
Diagnosis of adult

Adult male $285 \mu \mathrm{m}$ long (not including mouth tube), with 8 uniform clavoscalids, being long and paddle-like, with serrate tips. Double organ formed by two midventral spinoscalids of the second row, close but not fused and slightly different from other scalids of the same row. Fourth row with two alternating different types of spinoscalids, type ss4a with a double base and type ss $4 b$ with a single base and elongated claw-like tip; spinoscalid rows 4-8 with 30 jointed spinoscalids. Spinoscalids of row 9 consists of 30 elongate spindleshaped spines alternating with 30 round structures. Each round structure has two small teeth. Neck with 15 simple trichoscalids. Lorica with 40 longitudinal folds or plicae, and two transverse constrictions in its anterior end plus a single one near the posterior end.

\section{Diagnosis of Higgins larva}

Mouth cone consists of three parts and hexaradial symmetry; eight clavoscalids with swollen bases and fingerlike tips. First row of spinoscalids elongate; the two midventral very enlarged, modified and fused at their bases. Spinoscalid rows 3, 4 and 5 claw-like, with a modified middorsal spinoscalid in the fifth row. Compound spinoscalids in row 6 , with a fringed plate and an associated triangular plate; the midventral spinoscalid of this row is modified. Row 7 with compound spinoscalids consisting of an upper plate or shield and a lower shelf-like pointed plate; middorsal spinoscalid of this row strongly modified as a double plate with a conspicuous hooked extension. Thorax with five rows of folded cuticle appearing as plates. Two pairs of anterior hairy setae between thorax and lorica; lorica with 20 longitudinal plicae; no transverse folds. One dorsal pair of setae with swollen basis and one ventral pair of shorter setae. Toes relatively short and broad.

Material examined

\section{Type material}

The holotype is an adult male with fully developed testes collected on October 9, 1990, from sample L-30, and mounted (Glycerol and modified Hoyer's medium) on slide SL1-001 (ZMUC-LOR 660). Paratypes include one male inside larval and postlarval exuviae (slide SL1-005; ZMUC-LOR 661, sample L-61) and 30 larvae from samples L-29, L-30, L-55 and L-61. Six larvae from sample L-29 were mounted on stubs for scanning electron microscopy. Type material has been deposited in the Zoological Museum, Natural History Museum of Denmark, Copenhagen, under accession numbers ZMUC-LOR 660 to 689 . A total of 38 specimens of the new species of Rugiloricus were studied.

\section{Additional material}

Two additional specimens from L-29 (ZMUC-LOR 690 to 691) were found. One is an adult male and the other is a larva. Features of both specimens fit with the genus Pliciloricus, but could not be assigned to any of the described species. This material could not be described in detail, nor could the larval specimen be identified as conspecific with the adult specimen.

\section{Etymology}

The species is named in honor of Manuela Mayo, wife of the first author, for many years of loving support.

Description of the adult

The holotypic specimen is an adult male, $285 \mu \mathrm{m}$ long, measured from the tip of the partially extended mouth cone (mouth tube not included) to the posterior end of the lorica (Figs. 2a, 3). Maximum body width is measured in the thorax region, reaching $115 \mu \mathrm{m}$.

The mouth cone has three sections (Figs. 2c, 3). The proximal or first one is stalk-like and inserts in the introvert at the center of the ruff (see below). This section is not extended in the specimen. The second, or middle section, is broad and lantern-like and in the holotype appears directly on the ruff. Four cuticular, longitudinal oral ridges bifurcate soon distally, ending as eight free tips. Minute, short spinulae can be seen alternating with the free points of the oral ridges. This middle section ends with a closing apparatus of eight triangular plates forming a pyramid-like structure when closed. The third section is the mouth tube, completely withdrawn in the specimen, which cannot be described.

The introvert is hemispherical and $75 \mu \mathrm{m}$ long. A conspicuous ruff of cuticular ridges and folds is found in its anterior end (Fig. 3). Nine concentrical rows of scalids cover the introvert arranged along the anterior-posterior body axis (Figs. 2a, b, 3, 4). The first row is formed by eight clavoscalids (cs) directed forward. All clavoscalids are flat, feather-like appendages $150 \mu \mathrm{m}$ long. They have a short, bulbous base and a long shaft in which two longitudinal ridges or ribs divide the surface into two lateral vanes and a central band (Fig. 3). The central band narrows to the distal end of the clavoscalid, where the two ribs join. The remaining two vanes are flat, smooth and undecorated. The outer vane is shorter and ends joining the tip of the central strip, whereas the inner vane is longer, ending with a terminal point and three short spines on its distal edge. The dorsalmost pair of clavoscalids is slightly different in that they have a single rib each, and hence, no central strip exists. 

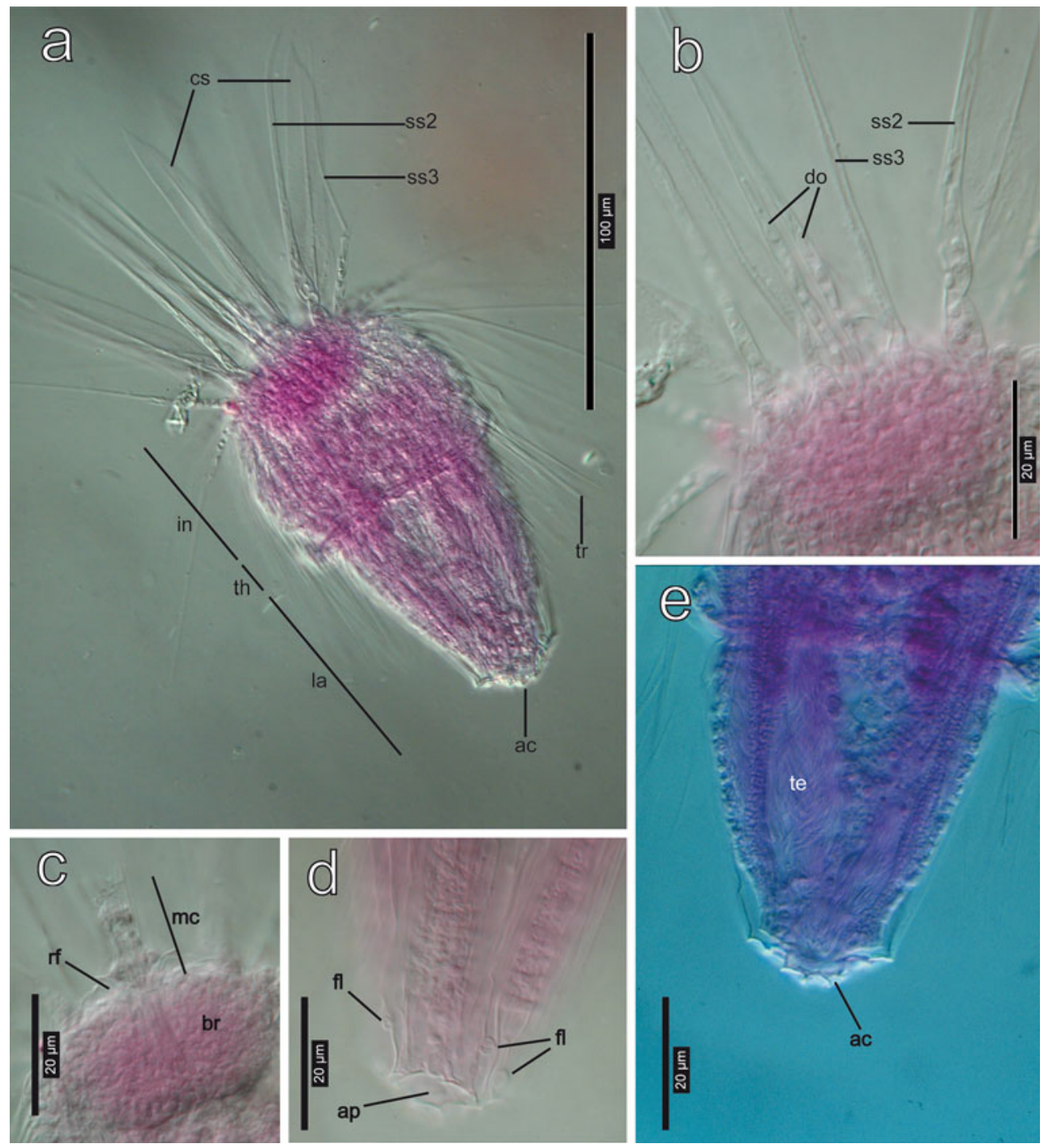

Fig. 2 Light micrographs of holotypic male of $R$. manuelae sp. nov. a Habitus of whole specimen. Note the feather-like clavoscalids. b Anterior end of adult. Note the unfused scalid forming the double organ. c Brain and mouth cone. The first (proximal) section of the mouth cone (stalk) is retracted and surrounded by the brain. d Anal

The second row (sr2) is formed by nine scalids (ss2) (Figs. 3, 4), distributed into seven spinoscalids plus the midventral double organ. The seven regular spinoscalids (ss2) are long appendages $(170 \mu \mathrm{m})$ with no articulations or specializations, except for a slightly bulbous proximal third showing a dorsal spinose projection. Distally, two small constrictions give a finger-like appearance to the tip of the spinoscalid, which ends claw-pointed.

The double organ (do) is formed by the midventral pair of spinoscalids of this second row (Figs. $2 b, 3,4$ ). They are very similar if not identical to the other spinoscalids of the row, including the spinose projection and the finger-like tip. They are inserted on the introvert independently, but very close to each other, at both sides of the ventral midline. field with P-flosculi. e Loricate abdomen. Note the large testes full of sperm. $a c$ Anal cone, ap anal plate, br brain, cs clavoscalid, do double organ, $f l$ flosculum, in introvert, $l a$ loricate abdomen, $m c$ mouth cone, $r f$ ruff, $s s$ spinoscalid (followed by the corresponding row number), te testes, $t h$ thorax, $t r$ trichoscalid

The third row of spinoscalids ( $\mathrm{sr} 3$ ) comprises 15 appendages, all similar and $150 \mu \mathrm{m}$ long (Figs. 3, 4). They comprise two segments. The proximal one has a double bulbous base ending distally in a tubercular joint armed with two lateral spines. The distal segment is an elongated acicular spine with no specializations.

The 30 spinoscalids of the fourth row (sr4) are differentiated into two alternating types, namely types A (ss4a) and B (ss4b) (Figs. 3, 4). Type A scalids (15) are attached to the introvert by a double base and have three segments: the proximal segment, $50 \mu \mathrm{m}$ long, resembles the previous row and articulates with the two segments of the distal, elongated piece $(90 \mu \mathrm{m})$. Type B scalids (15) have a single base and are also three jointed, with two short, bulbous 


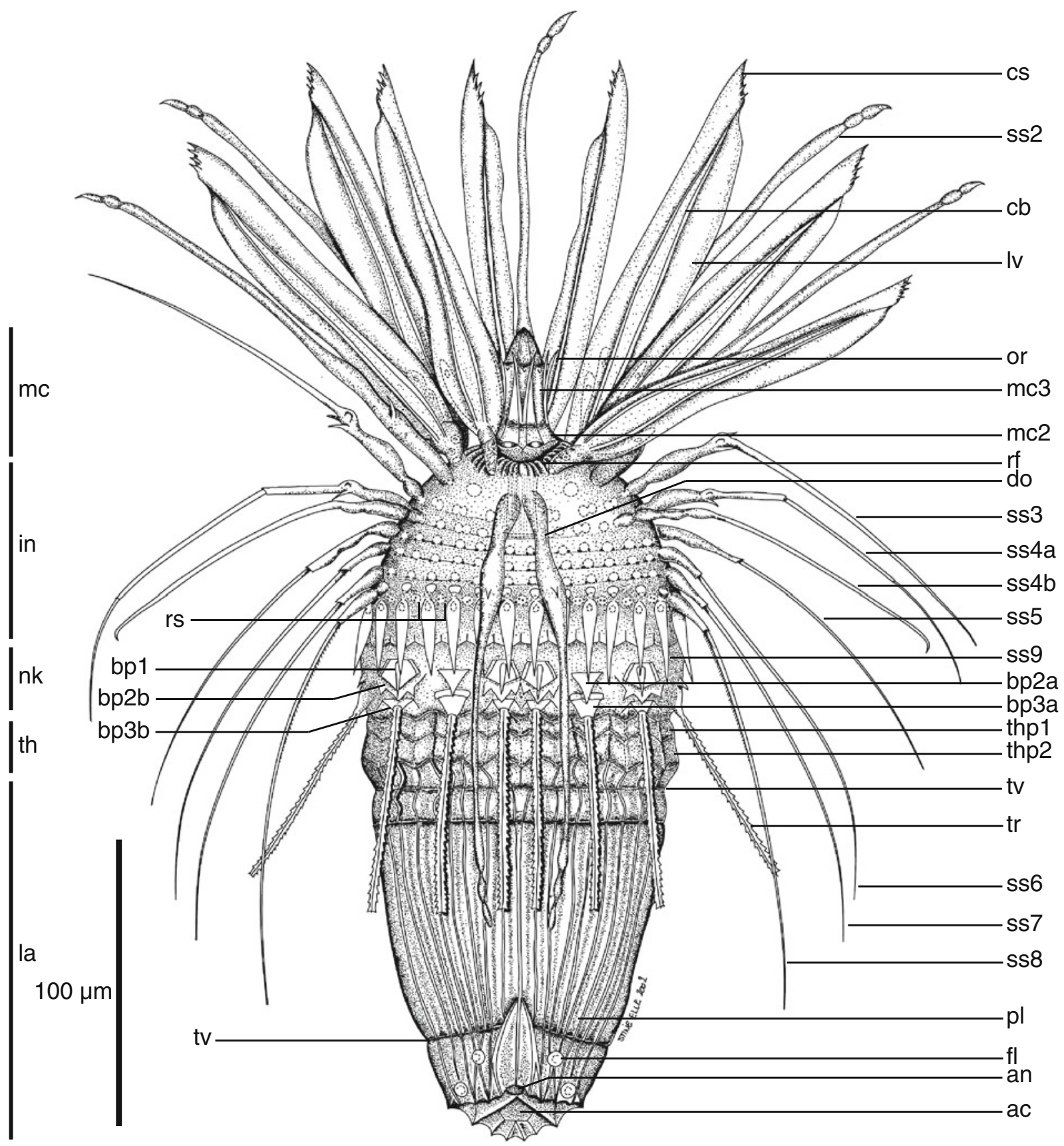

Fig. 3 Line drawing of holotypic male, ventral view. The different body sections are indicated in the left margin. Scalids from rows 2 to 8 are omitted for clarity, and only scalid bases are shown. ac Anal cone, $a n$ anus, $b p$ basal plate, $c b$ central band of clavoscalid, $c s$ clavoscalid, do double organ, $f$ flosculum, in introvert, la loricate abdomen, $l v$ lateral vane of clavoscalid, $m c$ mouth cone, $n k$ neck, or oral stylet, $p l$ plica, $r f$ ruff, $r s$ round structure, ss spinoscalid, th thorax, thp thorax plate, $t r$ trichoscalid, $t v$ transverse constriction basal pieces and an elongated distal piece $85 \mu \mathrm{m}$ long with a curved, claw-like tip.

Rows 5 to 7 are composed of 30 scalids each, with a single base and two segments, a short proximal one and a long, acicular distal one (Figs. 3, 4). The proximal segment in row 5 is $35 \mu \mathrm{m}$ long and $25 \mu \mathrm{m}$ in rows 6 and 7; the distal segment is $100 \mu \mathrm{m}$ in row 5 and up to $135 \mu \mathrm{m}$ in rows 6 and 7. The 30 scalids of row 8 have the same structure and size as the preceding ones, but their distal piece is finely serrated. The last scalid row (sr9) on the introvert comprises 30 much shorter scalids, shaped as elongated beaks $30 \mu \mathrm{m}$ long. Thirty round cuticular structures with 2 minute teeth each appear alternate with the scalids of the 8 and 9 rows. 
a

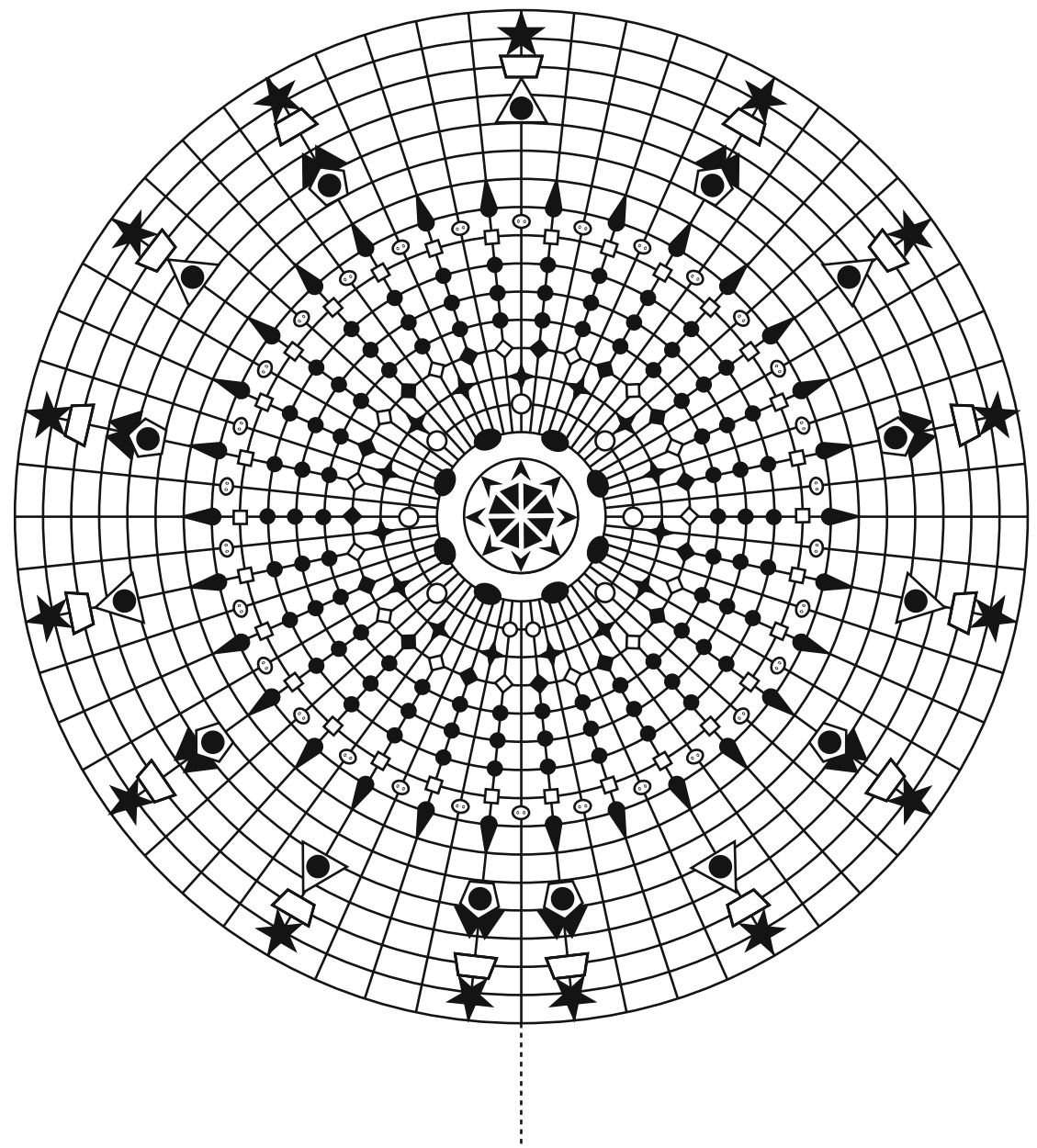

b

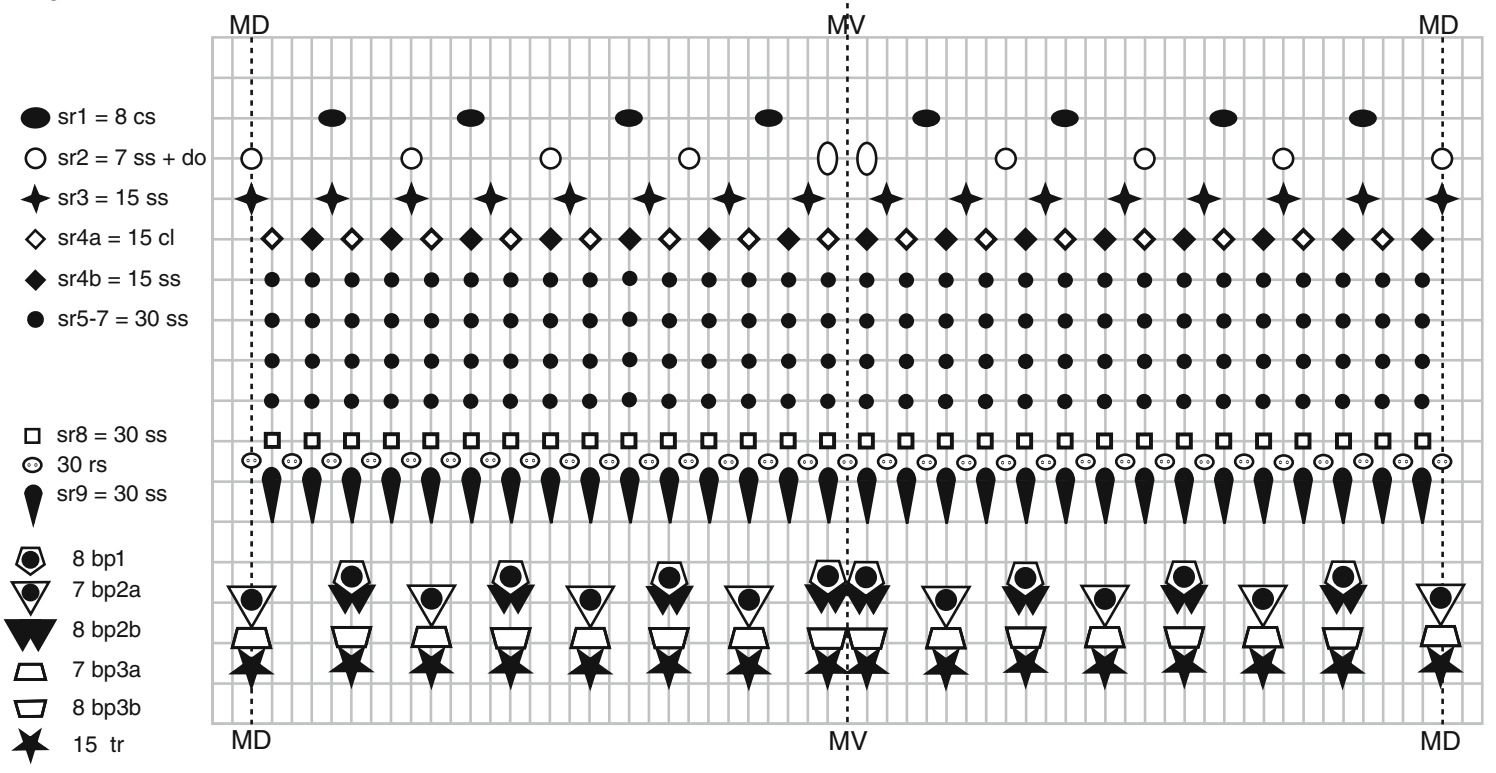

Fig. 4 Diagrams of scalid distribution in adult introvert. a Polar diagram. b Planar projection. $b p$ Basal plate, $c l$ claw-like scalid, $c s$ clavoscalid, $d o$ double organ, $r s$ round structure, $s r$ scalid row, ss spinoscalid, $t r$ trichoscalid

The next region (neck) of the adult body is $25 \mu \mathrm{m}$ long and has three rows of basal plates, and 15 single trichoscalids (tr) are found (Fig. 3). The anterior first row is formed by 8 pentagonal basal plates (bp1) provided with a spine $12 \mu \mathrm{m}$ long directed backward. Two types of basal plates appear in the middle second row: 8 plates (bp2a) 
with three points directed posteriorly, located directly below bp1 plates and alternating with 7 plates (bp2b) of triangular shape. The posterior neck row contains 15 basal plates distributed into two types: 8 trapezoid plates with rectangular bases (bp3a) alternating with 7 complex trapezoid-triangular plates (bp3b). The arrangement of all these plates around the introvert (Fig. 4) makes that two bp1 plates, two bp2a plates and two bp3a plates appear closely adjacent at the ventral midline. Fifteen single trichoscalids $70 \mu \mathrm{m}$ long articulate on the basal plates of the third row, both types A and B. Trichoscalids are flat, ribbon-like, with serrated margins and a central ridge.

A transverse constriction just below the trichoscalid plates marks the beginning of the thorax (Fig. 3). This body region is only $20 \mu \mathrm{m}$ long and covered by poorly defined cuticular plates, loosely arranged into two rows.

The abdominal lorica has 40 longitudinal folds or plicae (Figs. 2a, 3). Two transverse constrictions appear at the anterior end, near the thorax, and two additional transverse constrictions are located at the posterior $1 / 4$ of the abdominal length. The two midventral plicae form a pointed oval area at the posterior end of the abdomen. The last transverse constriction leaves a posteriormost anal cone area showing 8-10 anal plates (Figs. 2d, e, 3) although this number, especially at the dorsal side, is difficult to assess. Two of the midventral anal plates are starshaped. Two pairs of P-flosculi can be seen ventrally between the two posterior constrictions and one pair dorsally in the same area. The anus is located ventrally at the point where the anal cone meets the pointed oval area referred to above.

Internally, the introvert contains the relatively large brain (Fig. 2c), and the pharyngeal bulb is located inside the mouth cone. A pair of well-developed testes, elongated and full of matured spermatozoa, is located dorsolaterally inside the abdomen (Fig. 2e).

\section{Description of the Higgins larva}

A total of 36 larval specimens of different sizes $(85-285 \mu \mathrm{m})$ and in different states of retraction were studied. From the available material, it is not possible to establish any categories by size, so the number of larval instars cannot be determined. The fully developed Higgins larva, assumed as the penultimate stage, has the same body regions as the adult: mouth cone, introvert, neck, thorax and abdomen (Figs. 5a, 6). At least the introvert can be retracted within the abdominal cavity (Fig. 5b, c).

Mouth cone is cylindrical in shape; the terminal mouth is surrounded by six rounded lobes of alternating sizes, the bigger ones with a longitudinal ridge (Figs. 5d, 6). No oral stylets could be observed. The pharyngeal bulb is located in the mouth cone which is a condition found in all Higgins larvae described so far; however, no internal armature could be observed.

The cylindrical introvert comprises of 8 circular rows of specialized cuticular appendages or scalids (Figs. 6, 7). First row is formed by 8 clavoscalids directed forward. All clavoscalids are similar with a bulbous base and a long shaft. The blunt tip is slightly swollen and curved, giving the clavoscalid a finger-like appearance. The remaining scalids, rows $2-8$, are directed backward. The second row is composed by 15 scalids, elongated but much shorter than clavoscalids; a membranous flap connects the proximal region of the scalids to the introvert cuticle, leaving a free, blunt tip. The two midventral scalids of the second row are differentiated, appearing enlarged and stronger and nearly fused at their base, forming a larval version of the double organ of the adult (Figs. 5f, 6).

Seven scalids form the third row, with one at the middorsal line and leaving a midventral gap. All of them are short and claw-like with an anterior fringe of several spiny hairs. The fourth row is formed by 8 triangular scalids, alternating in position with the precedent row and leaving a middorsal gap (Figs, 5e, h, 7). The two midventral scalids are located below the double organ of the second row. All these scalids are very similar to the precedent row, except for the spiny fringe, that appears double. The fifth row is composed of 7 scalids, with a scale-like, fringed base and three-pointed tips, the central one longer than the lateral two (Figs. 5h, 6, 7). The middorsal scalid of this row (ss5md) is slightly modified, with the central tip longer and lanceolate (Figs. 5e, 6a, 7b). Seven scalids form the sixth row, alternating in position with the precedent ones. These scalids have a basal, round plate with lateral, fringed flaps and a distal, triangular tip (Figs. 5e, 6, 7b). Fringed flaps can vary from lobulated to finely serrate. The midventral scalid (ss6mv) is modified as a single oval plate with lobulated edges and one pair of triangular tips (Figs. 5f, 6b ,7b). The seven scalids of the seventh row (sr7) are modified as square shields or plates, alternating in position with the precedent row. These shields appear closely associated with the 7 scalids of the eighth row (sr8), shaped as widely based hooks directed anteriorly. At the middorsal line, the two scalids of rows seven and eight are combined into a double plate with a prominent hook (mdh, Figs. 5e,6a, 7). When the introvert is retracted, this middorsal hook is still visible at the anteriormost end of the larva, surrounded by the thorax plates (Fig. 5b).

The neck is a short region with no cuticular specializations, barely visible between the introvert and thorax and usually hidden under thorax plates, unless the specimen is exceptionally extended.

The thorax is formed by five rows of square, soft plates arranged accordion-like that fold concentrically over the introvert when retracted, closing the body (Figs. 5b, c, 6). 

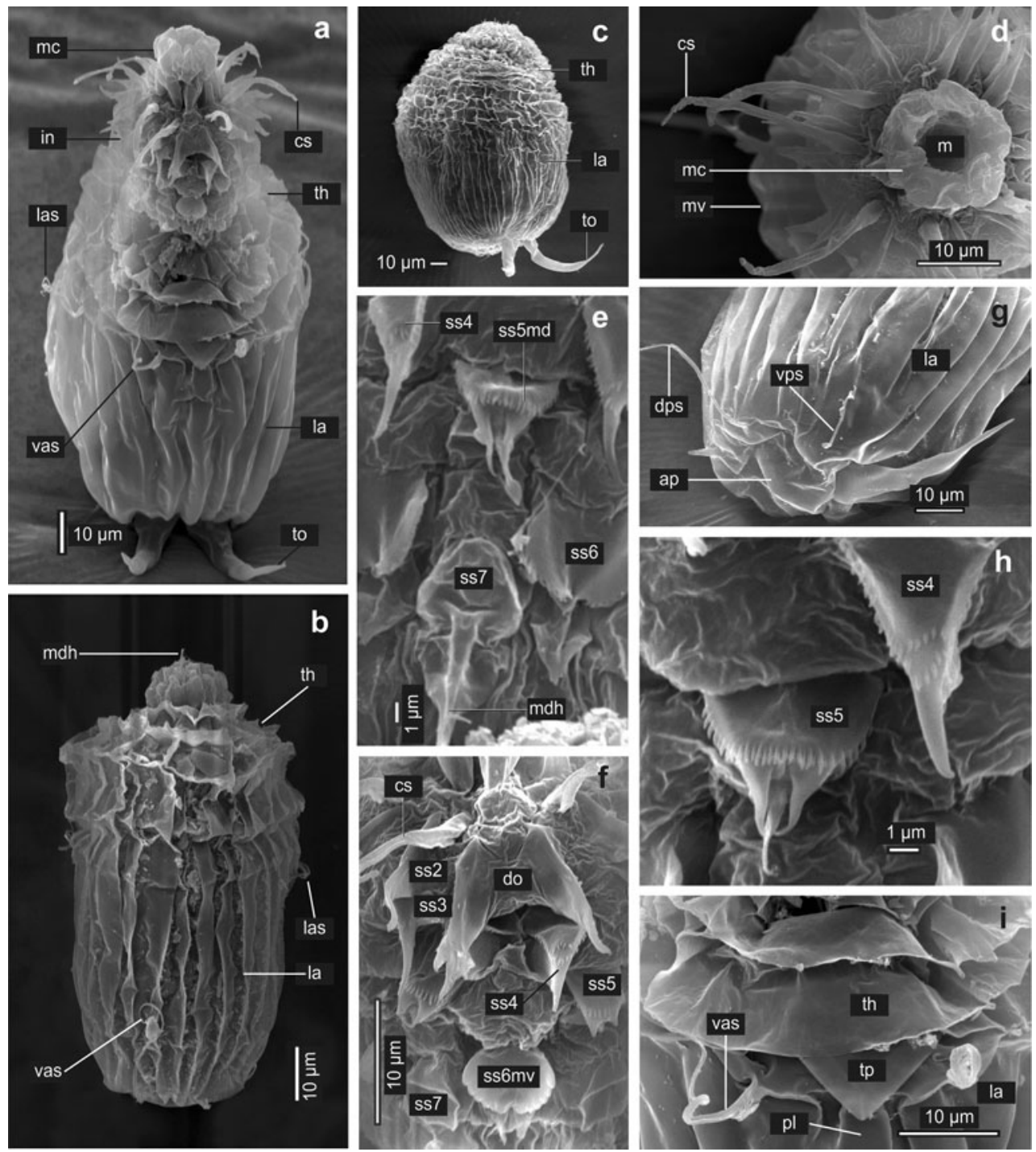

Fig. 5 Scanning micrographs of Higgins larva of $R$. manuelae sp. nov. a Ventral view of whole larva with the introvert extended. b Dorsal view of Higgins larva with introvert retracted. Note the middorsal hook extending from the top. $\mathbf{c}$ Lateral view of early-stage Higgins larva with the introvert retracted. Note the relatively long toes. d Apical view of Higgins larva. Note the mouth opening surrounded by six lobes. e Detail of scalids in middorsal region, rows 4-8. Note the middorsal hook and the modified scalid in row 5 . f Detail of scalids in midventral region. Note the modified midventral pair of scalids in row 2 and the modified midventral scalid of row 6 . g Lateral view of posteriormost body region. Note the toes, the anal

The anterior rows have 15 plates; this number can increase up to 17 in the posterior rows. Plates of the midventral line are wider than the others. Nevertheless, the exact number and shape of these soft thorax plates is somehow variable, and the state of the specimens prevents an accurate and consistent description that could be used with diagnostic or comparative purposes.

The abdomen is protected by a cuticular lorica, divided longitudinally into up to 20 folds or plicae. The surface of field and the lorical plicae. Only two pair of setae appears. h Detail of unmodified scalids of rows 4 and 5. i Midventral view of the anterior part of the lorica. Thorax plates can be seen over the conspicuous triangular plate of the lorica. ap Anal plate, $c s$ clavoscalid, do double organ, $d p s$ dorsal posterior seta, in introvert, $m$ mouth, $m c$ mouth cone, $m v$ midventral, $m d h$ middorsal hook, la loricate abdomen, las lateral anterior seta, ss spinoscalid (followed by the corresponding row number), ss5md middorsal scalid of scalid row 5 , ss $6 m v$ midventral scalid of scalid row 6, th thorax, to toe, $t p$ triangular plate of anterior region of lorica, vas ventral anterior seta, vps ventrolateral posterior seta

the lorica is smooth, without sculpture. A conspicuous triangular plate (tp) can be seen at the midventral anterior margin of the lorica, flanked at both sides by two pairs of lorical setae (Figs. 5i, 6). The ventral pair is shorter than the lateral one and both bear many stiff hairs all along their length. They are not branched, but simple stiff setae.

A large anal plate (ap) is located at the posterior end of the lorica, with round corners and a middorsal projection. One pair of toes directed anteriorly articulates ventrally on 


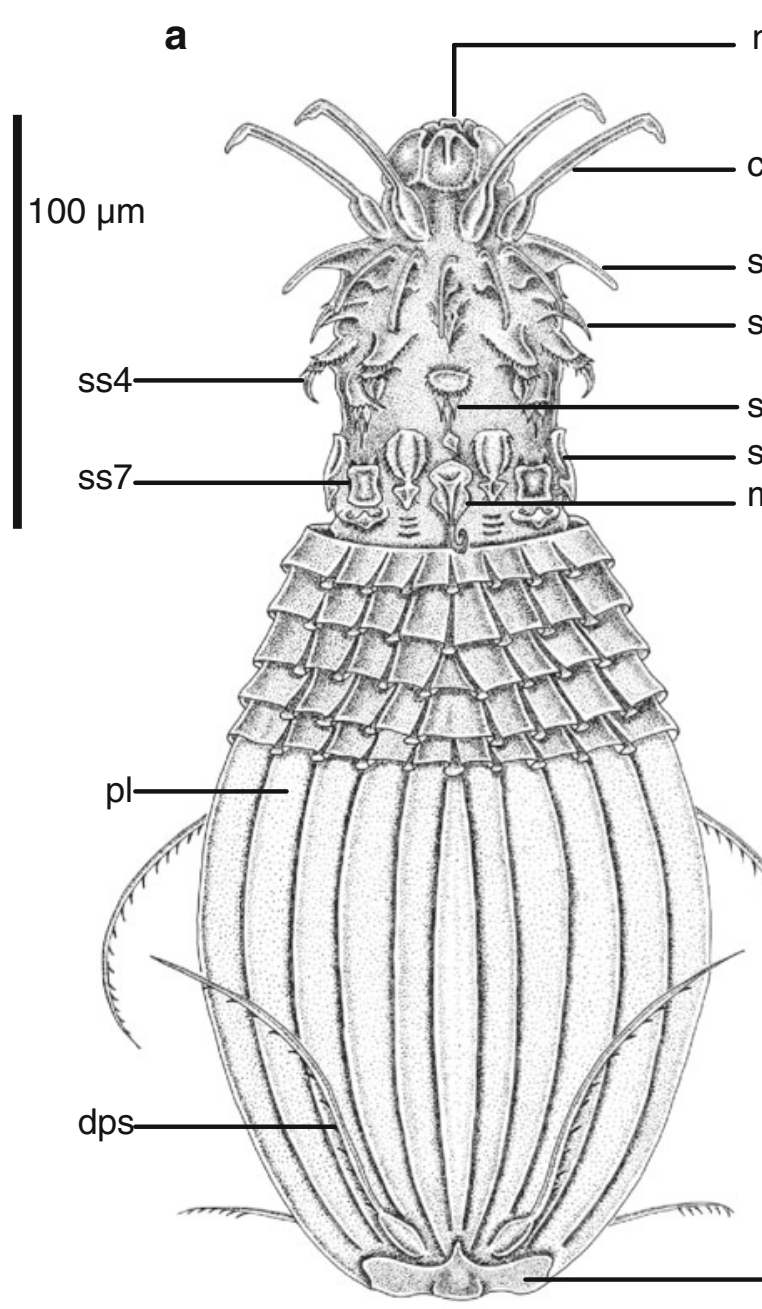

Fig. 6 Line drawings of penultimate Higgins larvae from SEM images. a Dorsal view. b Ventral view. ap Anal plate, cs clavoscalid, dps dorsal posterior seta, in introvert, la loricate abdomen, las lateral anterior seta, $m$ mouth, $m c$ mouth cone, $m d h$ middorsal hook, $p l$ plica,

the anterior margin of the anal plate (Figs. $5 \mathrm{~g}, 6 \mathrm{~b}$ ). Three parts can be distinguished on each toe, basal, medium and distal; the basal and medium ones are swollen or enlarged and the distal appears as an elongated and hollow tube. Two large abdominal glands are connected to the toes. Secretory material, presumably adhesive, can be seen inside the toes with DIC microscopy. One long dorsal pair and one shorter ventrolateral pair of setae appear at the posterior end of the lorica. Both pairs of setae are rigid with fine hairs. The swollen base lacks a jointed basal area. Flosculi are not present.

\section{Description of molting stage}

The finding of a single specimen consisting of a larval (last instar) exuvium enclosing a mature adult specimen (Figs. 8, 9) was very fortunate because it allowed to b

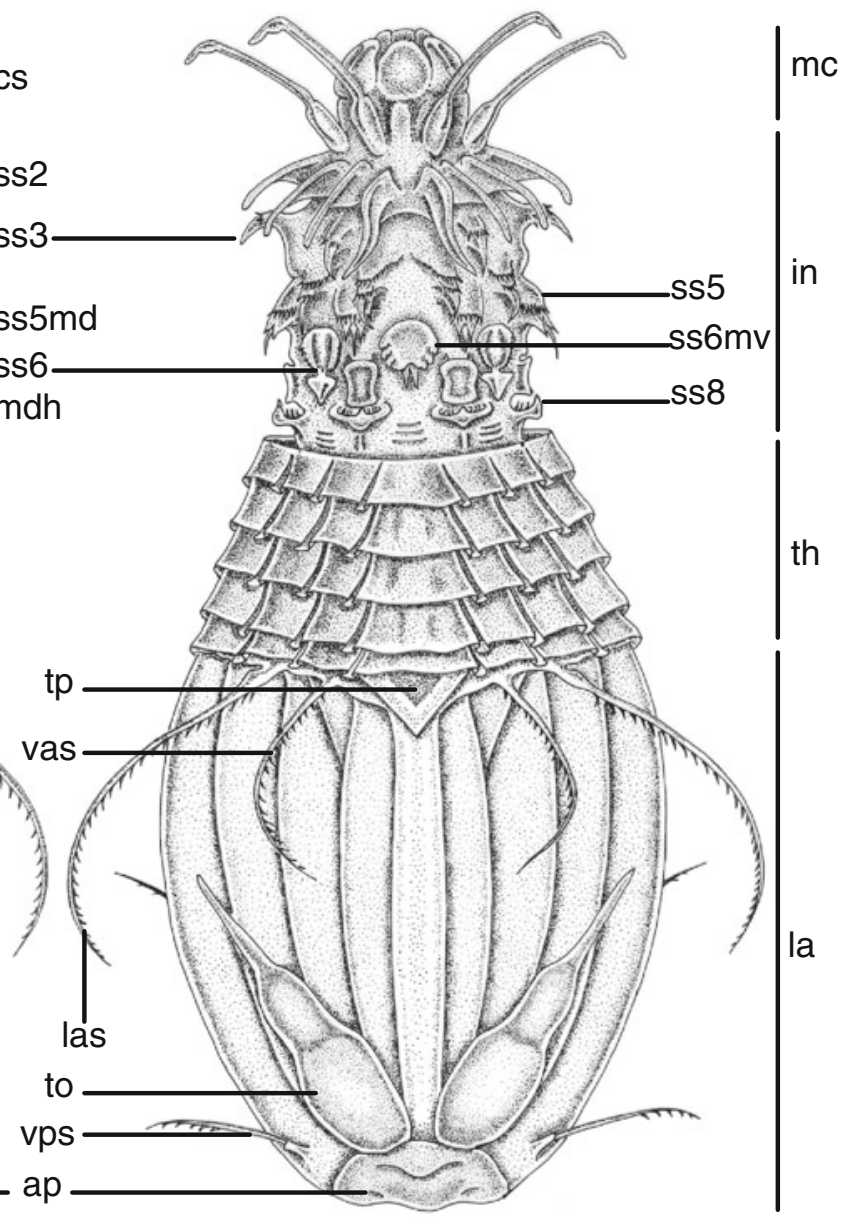

ss spinoscalid (followed by the corresponding row number), ss $5 \mathrm{md}$ middorsal scalid of scalid row 5, ss6mv midventral scalid of scalid row 6 , th thorax, to toe, $t p$ triangular plate, vas ventral anterior seta, vps ventral posterior seta

describe the complete life cycle (Fig. 10) and also to relate beyond any doubt the larval individuals (Higgins larvae) with the adult specimen. In fact, this molting specimen shows three life stages of the same individual. A fully mature male is enclosed by a thin cuticular envelope representing a postlarval stage which in turn is contained inside the exuvium of a last instar Higgins larva.

The young adult is seen in dorsal view, with the introvert partially retracted (Fig. 8a). First and second sections of the mouth cone can be identified clearly as the same than in the holotypic adult as well as the ruff in the mouth cone basis. The scalids of the introvert are joined into a thick bundle pointing anteriorly; only scalids of rows 8 and 9 could be distinguished clearly and identified with the corresponding ones in the holotype. Five of 15 single trichoscalids with same structure and length as in the holotype can be seen from the dorsal side. Their respective basal 
Fig. 7 Diagrams of scalid distribution in larval introvert. a Polar diagram. b Planar projection. Scalid types are illustrated in the left margin. cs Clavoscalid, do double organ, $m d h$ middorsal hook,

$m v$ midventral, $s r$ scalid row, ss spinoscalid
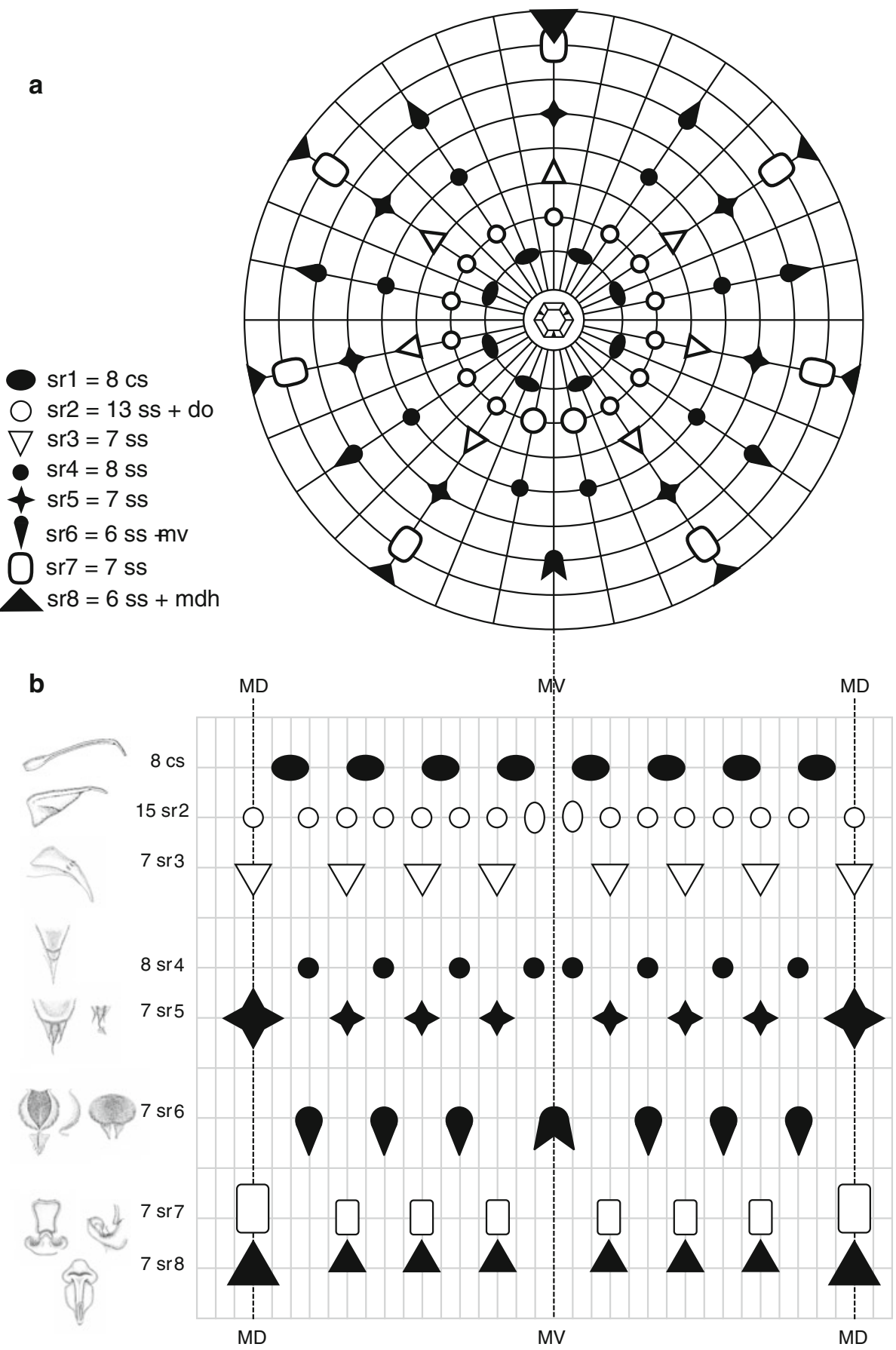

plates show also the same alternating types described above. Some of the trichoscalids perforate the thin postlarval cuticle that envelopes the young adult (Fig. 8f). The loricate abdomen shows longitudinal plicae although no transverse constrictions could be detected. The anal cone area has two star-shaped anal plates, which is a condition found in the holotypic adult, as well as two dorsal flosculi. Internally, a large brain surrounds the retracted first section of the mouth cone, seen at the level of the trichoscalids in the specimen. Nine circular muscle bands are present in the abdomen, together with a pair of large testes, full of sperm (Fig. 8d).

The young adult is completely surrounded by a thin cuticular envelope representing a highly reduced postlarval stage (Fig. 8b). The postlarva lacks visible external structures or appendages, except for a lateral area where several rows of tiny spines can be identified as the reduced protoscalids of the postlarval introvert (Fig. 8e).

The outermost layer of cuticle found in this specimen corresponds to the last instar of the Higgins larva. The 

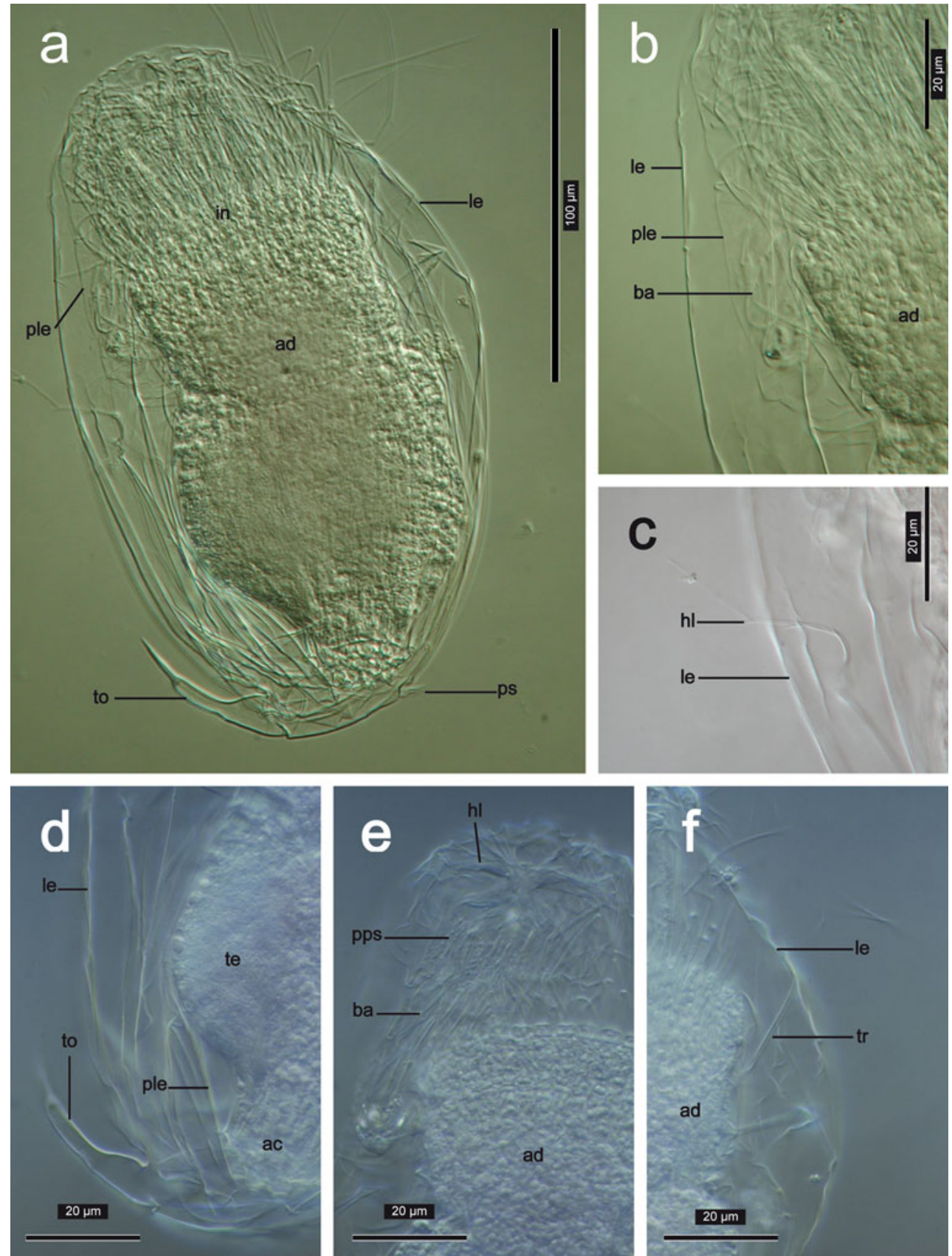

Fig. 8 Light micrographs of paratypic male inside larval and postlarval exuviae. a Habitus of whole specimen, lateral view. b Close view of the larval and postlarval cuticular envelopes enclosing the adult. Note the buccal armature of the larva. c Detail of the modified lateral seta of the larval exuvia. d Posterior view showing the larval toes and the adult. Note the anal cone and the testis of the latter. e Detail of the anterior end showing the hammer-like

larval introvert is completely withdrawn and reduced, appearing as a group of scalids below the postlarval protoscalids referred to above (Figs. 8e, 9). Also, the larval buccal armature (mouth cone) can be clearly identified in this area, although such structure has not been identified so clearly in all other larval specimens analyzed during our closing system and collar of the larva. Note the postlarval protoscalids. f Detail of the single trichoscalids of the adult, typical of the genus Rugiloricus. ac Anal cone, ad adult, $b a$ buccal armature, $h l$ hammer-like structure, in introvert, le larval exuvia, ple postlarval exuvia, $p p s$ postlarval protoscalids, $p s$ posterior seta, te testes, to toe, tr trichoscalid

study. Apically, the larval exuvium is closed by an oval to round plate with radial ridges, the so-called collar. Immediately below it, a hammer-like structure connects to the area where postlarval and larval scalids occur (Figs. 8e, 9). Five transverse folds appear in the anterior half of the specimen, in an area that should correspond to the larval 
Fig. 9 Line drawing of paratypic male inside larval and postlarval exuviae. Note the reduced setae at both the anterior and posterior regions of the abdomen of the last instar larva. ad Adult, ap anal plate, $b a$ buccal armature, $c$, collar, $d p s$ dorsal posterior seta, $h l$ hammer-like structure, la loricate abdomen, le larval exuvia, $m c$ mouth cone, ple postlarval exuvia, pps postlarval protoscalids, ss spinoscalid (followed by the corresponding row number), te testes, to toe, $t r$ trichoscalid, vas ventral anterior seta

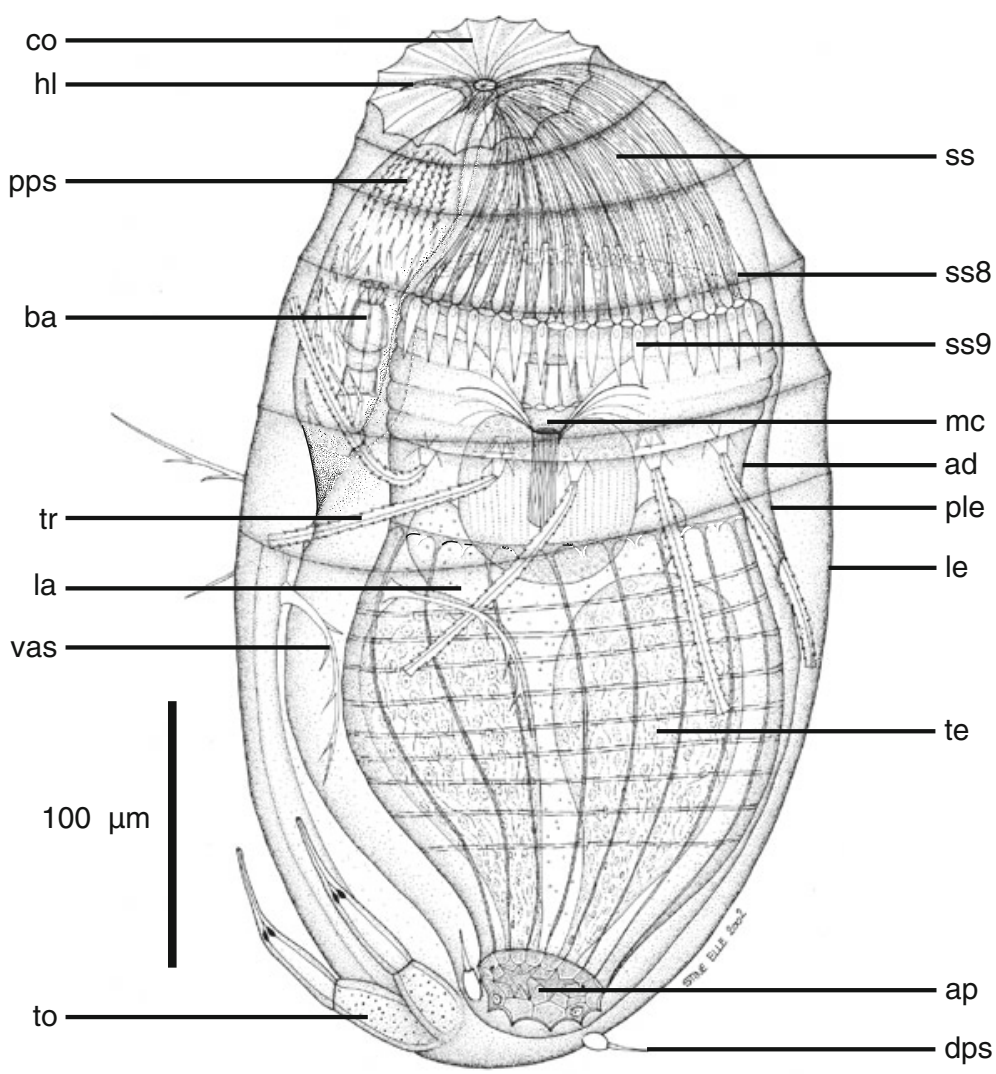

thorax. However, the cuticle appears smooth, without any plate as in the thorax of the penultimate Higgins larva. The abdomen shows barely distinguishable longitudinal plicae. Two pairs of anterior setae, ventral and lateral, remain visible, although they appear modified from their typical larval aspect (Figs. 8c, 9). Both pairs seem to be unbranched with fewer but very large hairs compared with the penultimate larva. The posterior end of the larval exuvium has a pair of toes with the same structure as described for the penultimate larvae, but with relatively reduced proportions (Figs. 8d, 9). Also, the two pairs of posterior setae appear here, but highly reduced to a basal, enlarged swollen part with a terminal pointed tip.

\section{Discussion}

Diagnostic features and comparisons

The genus Rugiloricus has been problematic from its very description (Higgins \& Kristensen 1986) where it is suggested to be paraphyletic. Since then, the genus is usually referred to in the loriciferan literature as comprising two more or less clear groups, namely the carolinensis-group (R. carolinensis Higgins \& Kristensen, 1986 and R. ornatus Higgins \& Kristensen, 1986) and the cauliculus-group
(R. cauliculus Higgins \& Kristensen, 1986, R. polaris Gad \& Martinez Arbizu, 2005, R. bacatus Heiner, 2008 and $R$. renaudae Kristensen et al., 2012). However, these two species groups have never been given a taxonomic status, mostly because their respective Higgins larvae are indistinguishable in practice. If finally the genus Rugiloricus is splitted into two, this will result with the erection of a new genus comprising the species of the $R$. carolinensis-group.

Rugiloricus manuelae sp. nov. is clearly assigned to the genus Rugiloricus because characteristic features are present in the adult stage, such as the large and pointed mouth cone, the leaf-like clavoscalids, the only slightly differentiated midventral scalids forming the double organ, only fused basally, the presence of 15 single trichoscalids and the presence of 30-60 lorical plicae. Larval diagnostic features include the presence of a modified middorsal scalid forming a prominent hook, toes with a broad base, intermediate segment and pointed tips, and only two pairs of posterior setae. However, it should be noted that several traits of the adult of the new species show a more Pliciloricus-like aspect: The anal cone is well developed, similar to species of Pliciloricus (cf. Pliciloricus diva Gad, 2009); three pairs of P-flosculi (two ventral and one dorsal) are present at the caudal end; the midventral plicae are modified as a posterior spindle-shaped area; the round structures alternating with spinoscalids of rows 8 and 9 are very 
Table 2 Comparison of adult characters of the species assigned to the $R$. carolinensis-group

\begin{tabular}{|c|c|c|c|}
\hline Common features & $\begin{array}{l}\text { R. carolinensis } \\
\text { Higgins \& Kristensen, } 1986 \\
\text { (†?) }\end{array}$ & $\begin{array}{l}\text { R. ornatus } \\
\text { Higgins \& Kristensen, } 1986 \text { ( } \widehat{o} \text { and }+ \text { ) }\end{array}$ & 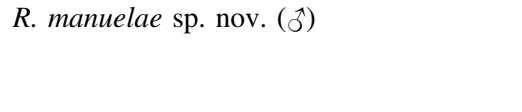 \\
\hline 1. Mouth cone & $\begin{array}{l}\text { Without external armature. } \\
\text { Mouth tube with } 6 \text { ridges }\end{array}$ & $\begin{array}{l}\text { Single ventral seta at mouth opening. } \\
\text { Second section with } 8 \text { double ridges }\end{array}$ & $\begin{array}{l}\text { Second section with } 4 \text { ridges bifurcating } \\
\text { distally. Eight triangular plates }\end{array}$ \\
\hline 2. Ruff & Absent & Present & Present \\
\hline $\begin{array}{l}\text { 3. Clavoscalid } \\
\text { structure }\end{array}$ & $\begin{array}{l}\text { Flat. Unsegmented. One } \\
\text { spinose tip }\end{array}$ & $\begin{array}{l}\text { Flat. Segmented. Longitudinal ridge in } \\
\text { proximal segment }\end{array}$ & $\begin{array}{l}\text { Flat. Unsegmented. Four spinose tips. Two } \\
\text { complete longitudinal ridges }\end{array}$ \\
\hline $\begin{array}{l}\text { 4. Variation in } \\
\text { clavoscalids }\end{array}$ & Data not available & $\begin{array}{l}\text { o } 8 \text { uniform clavoscalids with one cross- } \\
\text { wall at distal third } \\
\text { o } 8 \text { clavoscalids; six with two cross-walls } \\
\text { and two ventral with single cross-wall }\end{array}$ & Single longitudinal ridge in dorsal pair \\
\hline $\begin{array}{l}\text { 5. Spinoscalids of } \\
\text { second row }\end{array}$ & Elongate. Uniform & Dorsal ones elongate; ventral ones leg-like & Elongate. All uniform, with finger-like tip \\
\hline 6. Double organ & Not fused & Short; partly fused & Long; not fused \\
\hline $\begin{array}{l}\text { 7. All spinoscalids } \\
4-8 \text { rows }\end{array}$ & Filiform, spine-like & Filiform, spine-like; 8th row serrated & Filiform; spine-like; 8th row finely serrated \\
\hline $\begin{array}{l}\text { 8. Type B scalids of } \\
\text { fourth row }\end{array}$ & $\begin{array}{l}\text { No differences could be } \\
\text { found between A and B } \\
\text { types }\end{array}$ & Short; double claw tip & Very long; single claw tip \\
\hline 9. Scalids of 9 th row & Beak-like; short & Beak-like; short & Beak-like; long \\
\hline 10. Round structures & Between 8th and 9th rows & Not present & Between 8th and 9th rows \\
\hline $\begin{array}{l}\text { 11. Trichoscalid basal } \\
\text { plates }\end{array}$ & $\begin{array}{l}\text { bp1: } 8 \text { pentagonal with spine } \\
\text { bp2: absent } \\
\text { bp3a: } 7 \text { with short spine } \\
\text { bp3b: } 8 \text { poorly defined }\end{array}$ & $\begin{array}{l}\text { bp1: } 8 \text { with spine }+7 \text { beak-like } \\
\text { bp2: } 7 \text { with long spine } \\
\text { bp3: } 15 \text { (8 large }+7 \text { small })\end{array}$ & $\begin{array}{l}\text { bp1: } 8 \text { pentagonal with spine } \\
\text { bp2a: } 7 \text { triangular } \\
\text { bp2b: } 8 \text { three-pointed } \\
\text { bp3: } 15 \text { trapezoid ( } 7 \text { large }+8 \text { small) }\end{array}$ \\
\hline 12. Trichoscalids & $\begin{array}{l}15 \text { single; flat with serrated } \\
\text { margins } \sim 30 \mu \mathrm{m} \text { long }\end{array}$ & $\begin{array}{l}15 \text { single; flat with serrated margins; } \\
\sim 55 \mu \mathrm{m} \text { long }\end{array}$ & $\begin{array}{l}15 \text { single; flat with serrated margins; } \\
\sim 70 \mu \mathrm{m} \text { long }\end{array}$ \\
\hline $\begin{array}{l}\text { 13. Lorica transverse } \\
\text { folds (constrictions) }\end{array}$ & Two: middle and posterior & Two: middle (zigzag) and posterior & $\begin{array}{l}\text { Four: two anterior }+ \text { two posterior. } \\
\text { Midventral pointed oval area at posterior } \\
\text { end }\end{array}$ \\
\hline 14. Anal cone & Plate-like; anus dorsal? & $\begin{array}{l}\text { Large plate surrounded by } 12 \text { small plates; } \\
\text { anus location unknown }\end{array}$ & $\begin{array}{l}8-10 \text { anal plates (two star-shaped); anus } \\
\text { ventral }\end{array}$ \\
\hline
\end{tabular}

A similar comparative table for the species in the R. cauliculus-group has been published by Kristensen et al. (2013)

similar to the "alternate plates" described in Pliciloricus leocaudatus (Heiner \& Kristensen 2005).

Rugiloricus manuelae sp. nov. clearly belongs to the $R$. carolinensis-group, by its slender shape, the lantern-like mouth cone, the unmodified ventral clavoscalids and the large anal cone. Table 2 summarizes comparatively important features of the species in this group. $R$. manuelae sp. nov. is easily distinguished by its unique feather-like clavoscalids, the elongated claw-like spinoscalids of the fourth row and the four transverse constrictions of the lorica. The new species is the first one included into the carolinensis-group since the description of $R$. carolinensis and R. ornatus (Higgins \& Kristensen 1986). None of these two species have been reported again. The original description of $R$. carolinensis clearly shows the adult coming directly from the last instar larval exuvium, so no postlarval stage exists (see Fig. 56 in Higgins and Kristensen, 1986). However, Gad (2009) reports the presence of "a delicate cuticle layer surrounding the adults" in the type material of $R$. carolinensis. It should be noted that the material examined by the authors is a single adult (inside larval exuvium) and 240 larvae.

Higgins and Kristensen (1986) suggest the existence of a postlarval stage in $R$. ornatus, which constitutes the first indication of a highly modified postlarva in a loriciferan life cycle. These authors state that the immature stage they describe is probably a postlarva because it has no toes or lorical setae. But in their description, the metamorphosed adult inside the larval exuvium is surrounded by a thin membrane, both in the allotype male and one male paratype (cf. Higgins \& Kristensen 1986, Figs. 85, 86). We suggest that such a membrane corresponds to the postlarval stage described herein for $R$. manuelae sp. nov., but the lack of larval appendages in $R$. ornatus remains as a mystery.

The highly reduced postlarva as a thin cuticle enveloping a young adult inside a larval exuvium has been reported several times in species of Rugiloricus and probably in the whole 
genus Pliciloricus (Kristensen \& Brooke 2002; Gad 2005b; Gad 2005c; Heiner 2005; Heiner \& Kristensen 2005; Heiner 2008, Type II postlarva of $P$. diva Gad, 2009). The molting stage of $R$. manuelae sp. nov. (Figs. 8,9) consists, therefore, of the cuticle of the larva, postlarva and the adult male. The last instar larva of $R$. manuelae sp. nov. is only found as the exuvium in the molting animal; however, it is clearly seen that this larva does not look like the penultimate stage of Rugiloricus, as evidenced by the poorly defined thorax plates, the shorter and slightly different anterior setae, the first and second reduced posterior setae and also the smaller toes. Surprisingly, these features resemble the last instar larva of $P$. leocaudatus (see Heiner \& Kristensen 2005, Fig. 7) except for the lack of the third posterior pair of setae in $R$. manuelae sp. nov. Furthermore, the adult male inside the molting specimen is clearly a Rugiloricus with only 15 single trichoscalids. In his life cycle studies of Pliciloricidae, Gad (2005a) has shown the same feature of reduction in the setae of the last instar larva of Pliciloricus, but there are still no observations of this reduced larva free in the sediment.

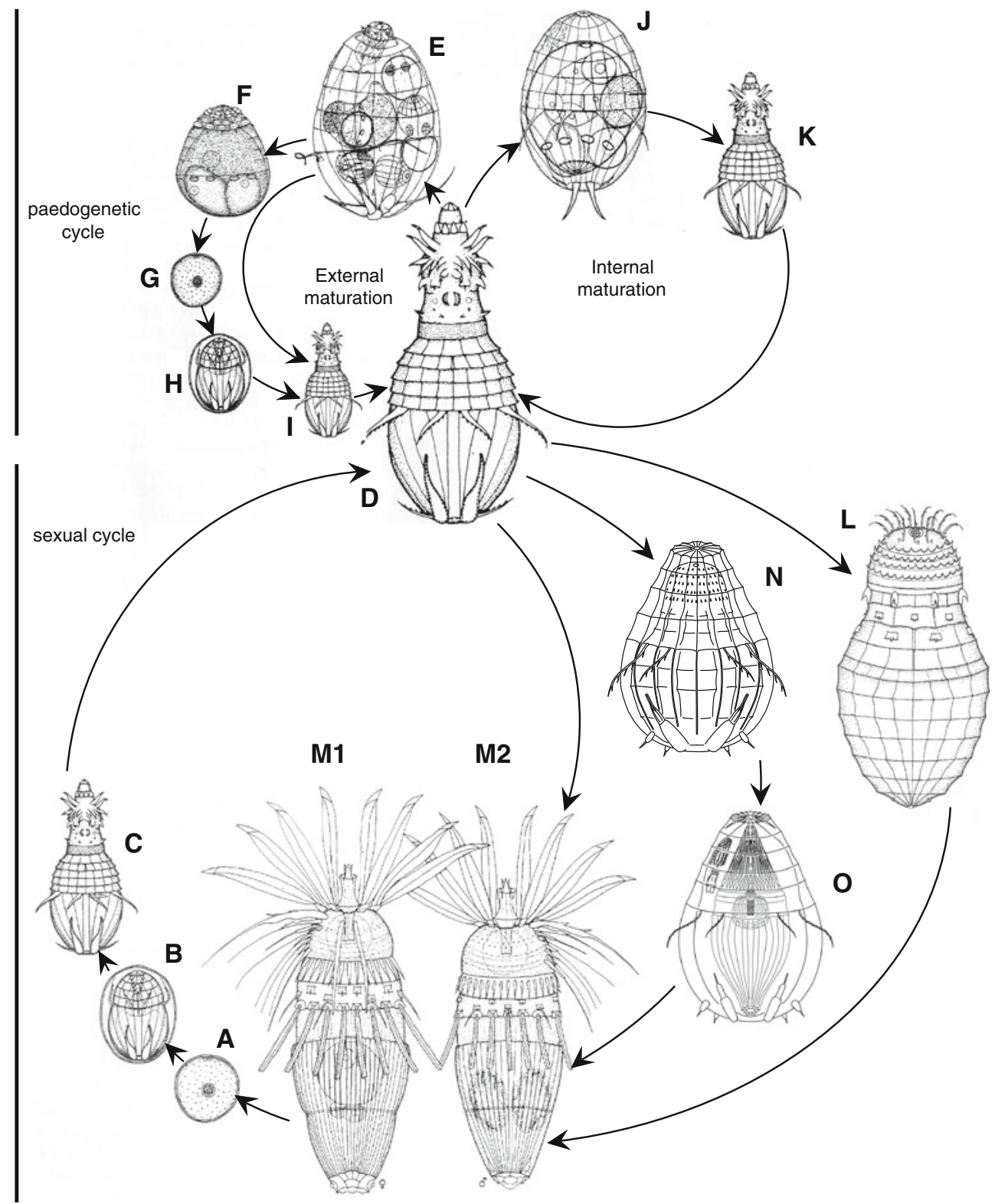

Fig. 10 A new emended life cycle of the family Pliciloricidae. Note the new loop of the sexual part of the cycle that includes the stages (n, o) described in this paper. Modified after Kristensen (2002), Kristensen and Brooke (2002) and Heiner (2008). a Egg. b Embryo. c First instar Higgins larva. d Late instar Higgins larva. e Penultimate larva with ghost larva and embryos inside. f Ghost larva. g Egg. h Embryo. i First instar Higgins larva. j Penultimate larva with ghost larva and embryos inside. k First instar Higgins larva. I Free postlarva. $\mathbf{m} 1$ Adult female. $\mathbf{m} \mathbf{2}$ Adult male. $\mathbf{n}$ Last instar Higgins larva with postlarva inside. o Last instar Higgins larva with postlarva and young adult inside 
Life cycle

The original discovery of loriciferans (Kristensen 1983) was a really fortunate event because the species described, Nanaloricus mysticus, belongs to a family Nanaloricidae that we know now has the simplest life cycle in the phylum, a fact only known with certainty very recently (Heiner and Neuhaus 2007; Kristensen et al. 2007).

First complication arouses with the description of a free strongly modified postlarval stage in R. cauliculus (Higgins \& Kristensen 1986). Successive complexity was added to loriciferan cycle with the discovery of parthenogenetic phases (neotenous larvae, Kristensen 1991; Kristensen \& Brooke 2002), ghost larva (Heiner 2008) and furthermore with the newly discovered Urnaloricidae (Heiner \& Kristensen 2009; Bang-Berthelsen et al. 2012) and the description of two modes of asexual life cycles: paedogenetic with external maturation as found in $R$. bacatus, $P$. pedicularis and Pliciloricus corvus and paedogenetic with internal maturation as in Titaniloricus (Gad 2005c; Heiner 2008).

The stage described herein for $R$. manuelae sp. nov. adds a new loop to the known life cycle in the family Pliciloricidae (Kristensen 2002; Kristensen and Brooke 2002; Heiner 2008). In this loop, a highly reduced, never free postlarva develops inside the last instar Higgins larva. This postlarval stage is probably a very short living and immediately molts into a young adult stage, still inside both larval and postlarval exuviae (Fig. 10o).

Discussions on the terms and concepts applied to loriciferan life cycles have been necessary to clarify and characterize these biologically complex processes ( $\mathrm{Gad}$ 2005c; Heiner 2008). The existence of paedogenetic and parthenogenetic phases or stages in life cycles are usually considered as biological adaptations of animal populations to situations of environmental stress, related to variable availability of resources or the presence of unstable or unpredictable habitats. Maybe, loriciferan populations reproduce normally in favorable conditions through a bisexual life cycle with adult males and females and several Higgins larva instars, as known in Nanaloricidae. When environmental conditions become harsh, sometimes a kind of dormant stage is needed, and a postlarva appears as in the genera Pliciloricus and Rugiloricus. Sometimes, this postlarval stage is present only as a hyper reduced envelope covering the adult still inside the Higgins larva exuvium (Pliciloricus and this paper). It is noteworthy that two types of postlarva, one with simplified features and other totally reduced to a thin cuticular layer, have been described by Gad (2009) in the same species, P. diva. Being this true, the presence and different developmental degree of postlarvae are probably related to environmental conditions that determine the type of life cycle regarding the rhythm of appearance of the life stages. The presence of a postlarval stage is then a feature shared by all members of the Pliciloricidae. However, the suggestion by Gad (2009) that all Loricifera pass through a postlarval stage has still not been confirmed.

On the other hand, favorable environmental or populational conditions would induce additional loops in the life cycle, through the appearance of paedogenetic larva that reproduce parthenogenetically, without the presence of male sperm and still in larval stages. This could be a way to increase population numbers rapidly when food resources are abundant and available, as a kind of shortcut of the general life cycle. Large amounts of food allow the larvae to grow to big sizes, a feature observed at the beginning of the parthenogenetic phase (Kristensen and Brooke 2002; Heiner 2008), and this is the trigger stimulus to reproduce parthenogenetically without intervening males. Such a life cycle strategy would also be useful as a mechanism of population recovery after an event of mass mortality related to the unstable habitat (Gould 1977). This reasoning is in good agreement with the proportion of different individuals (larvae/adults) found in sediment samples, in which larval forms outnumber adults up to $95 \%$ due to the parthenogenetic phase of the life cycle, dominant in spring and summer (Heiner 2005).

Consequently, although several variants of life cycles have been described in loriciferans-other than the well stabilized, simple Nanaloricidae-maybe they are not related to certain species or taxa, but only to environmental stress or conditions. Most of the described species have been found only once and with few specimens, and the life cycles reported, although complete, could represent only one of the several possible biological strategies of the species. Much research on loriciferan biology is still to be done to solve and clarify this and other questions in this enigmatic phylum.

Acknowledgments The authors want to thank Dr. Santiago Parra, Instituto Español de Oceanografía at La Coruña, who kindly provided us with the sediment samples used in this study. This study received financial support from the Research Projects CGL 2005-04310 and CGL 2009-08928 (Ministerio de Ciencia y Tecnología, Government of Spain), from the Synthesis Program of the European Union and the Carlsberg Foundation (Denmark). Stine Elle provided beautiful originals for the holotypic adult and the paratypic molting larva. Finally, Iben Heiner Bang-Berthelsen is acknowledged for offering valuable suggestions to the description of the new species.

\section{References}

Bang-Berthelsen IH (2008) Phylogeny of Loricifera based on combined morphological and molecular studies, Dissertation. University of Copenhagen, Denmark

Bang-Berthelsen IH, Schmidt-Rhaesa A, Kristensen RM (2012) Loricifera. In: Schmidt-Rhaesa A (ed) Handbook of zoology. 
Gastrotricha, Cycloneuralia and Gnathifera, vol 1. Nematomorpha, Priapulida, Kinorhyncha, Loricifera, pp 307-328

Danovaro RA, Dell'Anno A, Pusceddu A, Gambi G, Heiner I, Kristensen RM (2010) The first metazoa living in permanently anoxic conditions. BMC Biol 8:30

Danovaro RA, Gambi C, Pusceddu A, Dell'Anno A, Kristensen RM (2012) Anoxyphilic Loricifera. McGraw-Hill yearbook of science and technology. McGraw-Hill Companies, New York, pp 5-8

Gad G (2004) A new genus of Nanaloricidae (Loricifera) from deepsea sediments of volcanic origin in the Kilinailau Trench north of Papua New Guinea. Helgol Mar Res 58:40-53

Gad G (2005a) Life history stages of Loricifera: their morphology and position in the life cycle. Dissertation. Carl von Ossietzky Universität, Oldenburg

Gad G (2005b) Successive reduction of the last instar larva of Loricifera, as evidenced by two new species of Pliciloricus from the Great Meteor Seamount (Atlantic Ocean). Zool Anz 243:239-271

Gad G (2005c) A parthenogenetic, simplified adult in the life cycle of Pliciloricus pedicularis sp.n. (Loricifera) from the deep sea of the Angola Basin. Org Div Evol 5:77-103

Gad G (2009) A clearly identifiable postlarva in the life cycle of a new species of Pliciloricus (Loricifera) from the deep sea of the Angola Basin. Zootaxa 2096:50-81

Gad G, Martínez Arbizu P (2005) First description of an Arctic Loricifera-a new Rugiloricus-species from the Laptev Sea. Mar Biol Res 1:313-325

Gould SJ (1977) Ontogeny and phylogeny. Belknap Press of Harvard University, Cambridge

Heiner I (2005) Preliminary account of the Loriciferan Fauna of the Faroe Bank (NE Atlantic) BIOFAR proceedings. Ann Soc Scient Faeroensis Suppl 41:213-219

Heiner I (2008) Rugiloricus bacatus sp. nov. (Loricifera-Pliciloricidae) and a ghost-larva with paedogenetic reproduction. Syst Biodivers 6:225-247

Heiner I, Kristensen RM (2005) Two new species of the genus Pliciloricus (Loricifera, Pliciloricidae) from the Faroe Bank, North Atlantic. Zool Anz 243:121-138

Heiner I, Kristensen RM (2009) Urnaloricus gadi nov. gen. et nov. sp. (Loricifera, Urnaloricidae nov. fam.), an aberrant Loricifera with a viviparous pedogenetic life cycle. J Morphol 270:129-153
Heiner I, Neuhaus B (2007) Loricifera from the deep sea at the Galapagos Spreading Center, with a description of Spinoloricus turbatio gen. et sp. nov. (Nanaloricidae). Helgol Mar Res 61:167-182

Higgins RP (1964) A method for meiobenthic invertebrate collection. Amer Zool 4:291

Higgins RP (1988) Kinorhyncha. In: Higgins R, Thiel H (eds) Introduction to the study of meiofauna. Smithsonian Institution Press, Washington

Higgins RP, Kristensen RM (1986) New Loricifera from Southeastern United States coastal waters. Smithson Contr Zool 438:1-70

Kristensen RM (1983) Loricifera, a new phylum with Aschelminthes characters from the meiobenthos. Z Zool Syst und Evolut-forsch 21:163-180

Kristensen RM (1991) Loricifera-a general biological and phylogenetic overview. Verh Dtsch Zool Ges 84:231-246

Kristensen RM (2002) An introduction to Loricifera, Cycliophora, and Micrognathozoa. Integ and Comp Biol 42:641-651

Kristensen RM, Brooke S (2002) Phylum Loricifera. In: Young CM (ed) Atlas of marine invertebrate larvae. Academic Press, San Diego, pp 179-187

Kristensen RM, Gad G (2004) Armorloricus, a new genus of Loricifera (Nanaloricidae) from Trezen ar Skoden (Roscoff, France). Cah Biol Mar 45:121-156

Kristensen RM, Shirayama Y (1988) Pliciloricus hadalis (Pliciloricidae), a new loriciferan species collected from the Izu-Ogasawara Trench, Western Pacific. Zool Sci (Japan) 5:875-881

Kristensen RM, Heiner I, Higgins RP (2007) Morphology and life cycle of a new loriciferan from the Atlantic coast of Florida with an emended diagnosis and life cycle of Nanaloricidae (Loricifera). Invert Biol 126:120-137

Kristensen RM, Neves RC, Gad G (2013) First report of Loricifera from the Indian Ocean: a new Rugiloricus-species represented by a hermaphrodite. Cah Biol Mar 54:161-171

Sørensen MV, Hebsgaard MB, Heiner I, Glenner H, Willerslev E, Kristensen RM (2008) New data from an enigmatic phylum: evidence from molecular sequence data supports a sister-group relationship between Loricifera and Nematomorpha. J Zool Syst Evol Res 46:231-239

Todaro A, Kristensen RM (1998) A new species and first report of the genus Nanaloricus (Loricifera, Nanaloricida, Nanaloricidae) from the Mediterranean Sea. Ital J Zool 65:219-226 